BIO-CONS, Jurnal Biologi \& Konservasi

Volume 3 No. 2, Desember 2021

p-ISSN : 2620-3510, e-ISSN: 2620-3529

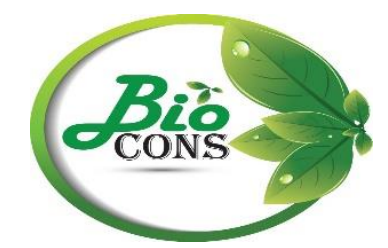

\title{
IMPLEMENTASI MODEL PEMBELAJARAN PROBLEM \\ BASED LEARNING (PBL) UNTUK MELATIH KEMAMPUAN BERPIKIR KREATIF MAHASISWA
}

\author{
IMPLEMENTATION OF THE PROBLEM BASED LEARNING (PBL) LEARNING \\ MODEL TO TRAIN STUDENTS' CREATIVE THINKING ABILITY \\ *Hanif Rafika Putri \\ Prodi Pendidikan Biologi \\ FKIP Universitas PGRI Argopuro Jember \\ *Email: rafika.putri13@gmail.com
}

\begin{abstract}
ABSTRAK
Pandemi COVID 19 memberikan dampak yang signifikan dalam bidang pendidikan, di antaranya pembelajaran dilaksanakan secara daring, sampai penghapusan ujian nasional bagi para siswa. Untuk mengatasinya, guru dituntut berpikir kreatif menciptakan ide baru dalam pelaksanaan proses pembelajaran. Kemampuan berpikir kreatif ini juga dilatihkan kepada para mahasiswa calon pendidik agar nanti siap dalam kondisi apapun. Salah satu model pembelajaran yang cocok untuk melatih kemampuan berpikir kreatif adalah Model Pembelajaran Problem Based Learning (PBL). Penelitian ini bertujuan untuk mengetahui peningkatan kemampuan berpikir kreatif mahasiswa setelah model pembelajaran PBL diterapkan. Jenis penelitian ini adalah pre experimental design dengan tipe one group pretest posttest design. Penelitian ini dilakukan pada mahasiswa semester 3 yang berjumlah 15 orang yang menempuh mata kuliah Belajar dan Pembelajaran. Hasil dari penelitian ini yakni terdapat peningkatan skor tes kemampuan berpikir kreatif dengan nilai ratarata 66,2 (kriteria cukup kreatif) dan $N$-gain 0,66 (kriteria sedang).
\end{abstract}

Kata kunci: Problem Based Learning (PBL), Berpikir Kreatif.

\begin{abstract}
The COVID-19 pandemic has had a significant impact in the field of education, including online learning, to the abolition of national exams for students. To overcome this, teachers are required to think creatively to create new ideas in the implementation of the learning process. This creative thinking ability is also trained for prospective educator students so that they will be ready in any condition. One of the suitable learning models to train creative thinking skills is the Problem Based Learning (PBL) Learning Model. This study aims to determine the increase in students' creative thinking skills after the PBL learning model is applied. This type of research is a pre experimental design with the type of one group pretest posttest design. This research was conducted on 3rd semester students, totaling 15 people who took Study and Learning courses. The result of this research is that there is an increase in creative thinking ability test scores with an average value of 66.2 (creative criteria) and $\mathrm{N}$-gain 0.66 (medium criteria).
\end{abstract}

Keywords: Problem Based Learning (PBL), Creative Thinking Ability. 


\section{PENDAHULUAN}

Pandemi COVID 19 yang terjadi selama kurun waktu hampir 2 tahun ini telah membawa perubahan dalam hampir semua aspek kehidupan. Dampak pandemi sangat terasa terutama dalam bidang kesehatan, sosial, pendidikan dan ekonomi. Bidang pendidikan misalnya, terdapat banyak sekali kesulitan selama pandemi berlangsung. Mulai dari pembelajaran yang tiba-tiba dilaksanakan secara daring, sampai penghapusan ujian nasional bagi para siswa. Begitu juga di kalangan pendidikan tinggi, dimana pembelajaran dilaksanakan full secara daring, bahkan saat wisuda pun juga dilaksanakan secara daring.

Pembelajaran di sekolah yang dilaksanakan secara daring menuntut guru melakukan berbagai inovasi agar pengetahuan yang diberikan tetap dapat dipahami oleh siswa. Guru dituntut berpikir kreatif menciptakan ide baru dalam pelaksanaan proses pembelajaran. Berpikir kreatif adalah sensitif dengan masalah-masalah; mencari informasi dari berbagai sumber eksternal; mencari alternatif solusi dari permasalahan sehari-hari; menduga, menguji berbagai solusi tersebut; dan mengkomunikasikan hasilnya (Torrance, 1965). Kemampuan ini, selain harus dimiliki oleh seorang guru, maka sebaiknya juga dilatihkan kepada para mahasiswa calon pendidik, agar mereka nantinya siap mendidik siswanya dalam situasi dan kondisi apapun. Berpikir kreatif merupakan persamaan kata (sinonim) dari berpikir divergen (Baer, 1993). Menurut Torrance,terdapat 4 karakter berpikir kreatif (berpikir divergen), yaitu; originality (kemampuan menghasilkan ide baru atau ide yang sebelumnya tidak ada), fluency (kemampuan menghasilkan banyak ide), flexibility (kemampuan menghasilkan ide-ide yang bervariasi), dan elaboration (kemampuan mengembangkan atau menambahkan ide-ide sehingga dihasilkan ide yang kompleks dan rinci atau detail) (Filasaime, 2008).

Menurut Bono (2007) kemampuan berpikir kreatif berfungsi untuk memperbaiki kehidupan, melakukan inovasi, menciptakan perubahan dan memperbaiki sistem. Filasaime (2008) juga menggambarkan bahwa kemampuan berpikir kreatif merupakan salah satu faktor penentu dalam pembangunan kepribadian dan pola tindakan. Oleh karena itu, kemampuan ini perlu dilatihkan kepada mahasiswa calon pendidik agar mereka terbiasa memiliki inovasi, mempunyai ide dan solusi untuk mengatasi berbagai permamsalahan, terutama masalah dalam bidang pendidikan.

Kenyataan yang terjadi di lapangan, banyak sekali guru yang merasa tidak siap melaksanakan proses pembelajaran secara daring, pertama kebingungan karena tidak menguasai teknologi informasi, dan yang kedua kebingungan menentukan metode apa yang akan digunakan saat pembelajaran dilakukan secara daring (Putra, 2020), sehingga pengembangan kemampuan berpikir kreatif perlu dilatihkan kepada para mahasiswa dalam 
mata kuliah Belajar dan Pembelajaran agar hal di atas tidak terjadi kepada mereka di kemudian hari. Kemampuan berpikir kreatif yang dilatihkan dalam jangka waktu tertentu akan membentuk pola pikir dan tindakan seseorang, yakni akan membuat seseorang terbiasa memiliki banyak ide untuk menyelesaikan permasalahan.

Salah satu model pembelajaran yang cocok untuk melatih kemampuan berpikir kreatif adalah Model Pembelajaran Problem Based Learning (PBL). Menurut Thomas (2000), model pembelajaran Project Based Learning merupakan suatu model pembelajaran yang meliputi pemberian pertanyaan dan masalah yang bermakna, kemudian melakukan pemecahan masalah, pengambilan keputusan berdasarkan pencarian berbagai sumber, pemberian kesempatan kepada anggota untuk bekerja secara kolaboratif, dan melakukan presentasi solusi yang diusulkan (dapat berupa produk nyata). Kelebihan dari model ini untuk melatih berpikir kreatif berdasarkan penelitian yang dilakukan oleh Antika (2017) adalah bahwa model pembelajaran Problem Based Learning (PBL) dapat meningkatkan kemampuan mahasiswa dalam pembiasaan berpikir kreatif.

\section{METODE PENELITIAN}

Penelitian ini dilaksanakan di Program Studi Pendidikan Biologi FKIP Universitas PGRI Argopuro Jember pada mahasiswa semester 3. Penelitian dilakukan pada mata kuliah Belajar dan Pembelajaran, dimana hasil akhir dari mata kuliah ini adalah produk atau ide yang diberikan mahasiswa untuk mengatasi problem pelaksanaan kegiatan pembelajaran di sekolah secara daring selama pandemi COVID 19 berlangsung. Penelitian yang dilakukan merupakan pre experimental design dengan tipe one group pretest posttest. Adapun pola penelitian one group pretest posttest design menurut Sugiyono (2008) adalah sebagai berikut (Gambar 1.):

$$
\mathrm{O}_{1} \times \mathrm{O}_{2}
$$

Gambar 1. Metode one group pretest posttest design (Sugiyono: 2008)

\section{Keterangan:}

$\mathrm{O}_{1}=$ nilai pretest (sebelum perlakuan)

$\mathrm{X}=$ perlakuan (model pembelajaran PBL)

$\mathrm{O}_{2}=$ nilai posttest $($ setelah diberi perlakuan)

Jumlah mahasiswa yang terlibat dalam penelitian ini berjumlah 15 orang. Pada desain ini tes yang dilakukan sebanyak dua kali, yaitu sebelum dan sesudah diberikan perlakuan 
(model pembelajaran PBL). Tes yang dilakukan adalah berdasarkan instrumen penilaian berpikir kreatif yang dikembangkan oleh Guilford. Tes ini digunakan untuk mengukur kemampuan berpikir divergen seseorang (Weilsenn, Guliford, Christensen \& Lewis, 1954).

Waktu pelaksanan penelitian ini adalah pada bulan Oktober - November 2021. Data yang digunakan adalah data kuantitatif dan data kualitatif. Data kuantitatif dari nilai pretestpostest untuk membandingkan perbedaan kemampuan berpikir kreatif mahasiswa sebelum dan sesudah perlakuan (penerapan model pembelajaran PBL). Sedangkan data kualitatif dalam penelitian ini adalah deskripsi kemampuan berpikir kreatif mahasiswa sebelum dan sesudah dilaksanakan pembelajaran.

\section{HASIL DAN PEMBAHASAN}

Hasil dari penelitian yang telah dilakukan berupa data kemampuan berpikir kreatif mahasiswa sebelum dan sesudah diterapkannya model Project Based Learning (PBL). Tes yang berupa Guilford Alternate Use yang digunakan dalam pengukuran kemampua berpikir kreatif mahasiswa. Tes ini mencakup komponen dari kemampuan berpikir kreatif, diantaranya originality, fluency, flexibility dan elaboration (Nur, 2014). Berikut adalah hasil tes kemampuan berpikir kreatif mahasiswa saat pretest dan posttest beserta skor $N$-gain (Tabel 1.).

Tabel 1. Hasil tes kemampuan berpikir kreatif dan skor $N$-Gain

\begin{tabular}{|c|c|c|c|c|c|c|}
\hline \multirow[t]{2}{*}{$\begin{array}{l}\text { Inisial } \\
\text { Maha } \\
\text { siswa }\end{array}$} & \multirow{2}{*}{$\begin{array}{l}\text { Niliai } \\
\text { Pre-Test }\end{array}$} & \multirow[t]{2}{*}{ Kriteria } & Niliai & \multirow[t]{2}{*}{ Kriteria } & \multirow[t]{2}{*}{$\begin{array}{l}N- \\
\text { Gain }\end{array}$} & \multirow[t]{2}{*}{ Kategor } \\
\hline & & & Post-Test & & & \\
\hline M 1 & 43 & $\mathrm{CK}$ & 59 & CK & 0,43 & Rendah \\
\hline M 2 & 34 & KK & 57 & CK & 0,50 & Sedang \\
\hline M 3 & 40 & KK & 66 & CK & 0,65 & Sedang \\
\hline M 4 & 24 & KK & 50 & CK & 0,46 & Sedang \\
\hline M 5 & 36 & KK & 56 & CK & 0,45 & Sedang \\
\hline M 6 & 40 & KK & 66 & $\overline{C K}$ & 0,65 & Sedang \\
\hline M 7 & 36 & KK & 56 & CK & 0,45 & Sedang \\
\hline M 8 & 51 & $\mathrm{CK}$ & 79 & K & 0,97 & Tinggi \\
\hline M 9 & 39 & $\mathrm{CK}$ & 67 & K & 0,68 & Sedang \\
\hline M 10 & 44 & $\mathrm{CK}$ & 67 & CK & 0,64 & Sedang \\
\hline M 11 & 43 & $\mathrm{CK}$ & 83 & $\mathrm{~K}$ & 1,08 & Tinggi \\
\hline M 12 & 47 & $\mathrm{CK}$ & 61 & $\mathrm{CK}$ & 0,42 & Sedang \\
\hline M 13 & 46 & $\mathrm{CK}$ & 76 & $\mathrm{~K}$ & 0,88 & Tinggi \\
\hline M14 & 51 & $\mathrm{CK}$ & 76 & K & 0,86 & Tinggi \\
\hline M 15 & 41 & CK & 74 & K & 0,85 & Tinggi \\
\hline
\end{tabular}




\section{Keterangan:}

$$
\begin{array}{ll}
\text { KK } & \text { : Kurang Kreatif } \\
\text { CK } & \text { : Cukup Kreatif } \\
\text { K } & \text { : Kreatif } \\
\text { SK } & \text { : Sangat Kreatif }
\end{array}
$$

Berdasarkan Tabel 1. di atas, hasil rata-rata dari kemampuan berpikir kreatif mahasiswa saat pretest adalah 41 dan saat posttest adalah 66,2 dengan kategori cukup kreatif. Setelah dilakukan perhitungan $\mathrm{N}$-gain, maka hasilnya adalah 0,66 dengan kriteria sedang.

Berdasarkan data yang diperoleh di atas, maka terdapat perbedaan hasil kemampuan berpikir kreatif mahasiswa setelah mendapat perlakuan yaitu diterapkannya model pembelajaran PBL. Indikator berpikir kreatif yang paling dominan mengalami peningkatan setelah posttest adalah originality dan fluency. Indikator ini menggambarkan bahwa mahasiswa mampu memberikan ide yang baru, orisinil dan berbeda antar satu dengan yang lain untuk mengatasi masalah selama pembelajaran daring dilakukan sekolah. Kemampuan mahasiswa mengeluarkan ide secara orisinil atau asli ini tidak lepas dari kemauan mereka dalam menambah pengetahuan dan pengalaman mereka, baik terjun langsung ke sekolah dengan melakukan berbagai pengamatan, juga menambah kemampuan mereka dengan mengikuti berbagai pelatihan secara daring. Indikator fluency atau kelancaran menunjukkan kemampuan seseorang untuk memproduksi ide sebanyak-banyaknya. Ide yang dihasilkan semakin banyak dan beragam, maka semakin banyak pula kemungkinan untuk memilih salah satu ide yang paling cocok diterapkan untuk memecahkan masalah yang muncul. Indikator ini mengalami peningkatan skor yang tinggi saat post test karena fasilitator, yaitu dosen mampu memberikan motivasi kepada mahasiswa untuk tidak malu dan insecure untuk menuliskan dan mengungkapkan ide yang mereka miliki. Mahasiswa sering diajak berdiskusi atas berbagai macam masalah dan diminta mengungkapkan ide mereka untuk mengatasi hal tersebut berdasar informasi yang mereka peroleh. Pembelajaran yang dilakukan secara kolaboratif antar mahasiswa yang terdapat dalam tahapan model pembelajaran PBL juga diaplikasikan dengan baik oleh mahasiswa, sehingga mereka mampu mengungkapkan banyak ide yang orisinil. Kegiatan ini dapat dilakukan dengan baik sehingga mahasiswa menjadi terbiasa menyampaikan berbagai macam ide atau pendapat dan alternatif solusi (Nur, 2014).

Indikator yang memiliki peningkatan rendah saat postest adalah flexibility dan elaboration. Indikator flexibility merupakan indikator yang menunjukan keragaman ide atau kemampuan mahasiswa untuk mengungkapkan berbagai macam jenis ide (berbeda-beda) dalam menyelesaikan masalah. Indikator ini tidak banyak mengalami peningkatan karena 
mahasiswa terkadang menganggap dirinya sudah menyampaikan ide yang berbeda, padahal setelah dianalisis lebih lanjut hasilnya sama saja dengan ide yang diungkap sebelumnya, hanya berbeda bahasa saja. Hal ini bisa ditingkatkan dengan melakukan pelatihan kemampuan berpikir kreatif dengan frekuensi yang lebih sering. Begitu juga dengan indikator elaboration. Indikator ini tidak mengalami peningkatan yang signifikan karena tidak semua mahasiswa memiliki wawasan yang luas untuk memperjelas ide yang mereka ungkapkan. Tetapi, terkadang mereka sudah ada yang memiliki wawasan luas, tetapi kesulitan menghubungkan konsep yang telah diperoleh sebelumnya dengan ide yang diungkapkan untuk menyelesaikan masalah.

Peningkatan kemampuan berpikir kreatif didukung oleh proses belajar yang dilakukan dengan langkah-langkah Project Based Learning (PBL). Pada langkah pertama yaitu penentuan proyek. Pada langkah ini, mahasiswa secara berkelompok diminta untuk menyusun instrumen observasi atau pengamatan ke sekolah yang telah ditentukan untuk mengetahui masalah apa saja yangsedang dialami oleh sekolah saat pembelajaran dilakukan secara daring. Model pembelajaran ini menurut hasil penelitian Grand (2005), dapat mengembangkan berbagai macam jenis kecerdasan (multiple intelligences), meningkatkan sistem dan domain pengetahuan, metakognisi pengetahuan yang meliputi proses memilih, bertanya, membagi informasi, menyusun hipotesis, dan proses pembuatan keputusan. Sehingga, model ini cocok untuk melatih kemampuan berpikir kreatif jika dilihat dari aspek elaboration.

Langkah kedua dari model pembelajaran Project Based Learning adalah perancangan langkah-langkah penyelesaian proyek dan penyusunan pelaksanaan proyek. Beberapa kegiatan yang dilakukan mahasiswa antara lain, melakukan kegiatan observasi ke sekolah, mencari sumber atau bahan untuk mengungkapkan ide pemecahan masalah, untuk kemudian mengeksekusi ide tersebut menjadi sebuah proyek yang akan dilaksanakan. Dalam pengembangan kemampuan berpikir kreatif diperlukan adanya masalah, kemudian mendefinisikannya masalah secara jelas, membuat dugaan dan kemungkinan perbaikannya, pengujian kembali atau mendefinisikan masalah dan mengkomunikasikannya (Antika, Nawawi, 2017).

Pada langkah ketiga adalah penyelesaian proyek dengan fasilitas dan monitoring tenaga pendidik. Pada langkah ini mahasiswa secara berkelompok menyelesaikan tugas proyek dengan bimbingan dosen. Kegiatan ini mendukung kemampuan berpikir kreatif pada aspek fluency yaitu kemampuan menghasilkan banyak ide, sebab dari berbagai permasalahan yang terjadi di sekolah mahasiswa dilatih untuk mencari berbagai solusi penyelesaiannya. Kegiatan ini juga melatih kemampuan flexibility, dimana mereka menghasilkan ide baru yang sangat 
beragam, bahkan ideide baru yang belum pernah dilakukan oleh peneliti sebelumnyaa (originality). Langkah selanjutnya pada model pembelajaran Project Based Learning adalah presentasi/ publikasi hasil proyek. Hal ini melatihkan kemampuan mengomunikasikan dan memungkinkan adanya saran atau kritik dari mahasiswa lainnya, kemudian memberi kesempatan untuk mengembangkan ide yang sudah ada (elaboration). Langkah terakhir adalah evaluasi proses dan hasil proyek. Mahasiswa pada akhir pembelajaran melakukan refleksi terhadap aktivitas dan hasil tugas proyek. Proses ini dapat dilakukan secara individu maupun kelompok. Pada tahap evaluasi dan refleksi ini, mahasiswa diberi kesempatan mengemukakan pengalamannya mulai dari awal mengerjakan tugas proyek hingga menyelesaikannya. Pada tahap ini juga dilakukan umpan balik terhadap proses dan produk yang telah dihasilkan.

\section{SIMPULAN}

Simpulan dari penelitian ini adalah implementasi model pembelajaran Project Based Learning (PBL) dapat melatihkan kemampuan berpikir kreatif mahasiswa, terutama aspek fluency dan originality. Hal ini sesuai dengan beberapa penelitian sebelumya, yakni penelitian Antika dan Nawawi (2017) yang menyatakan bahwa model pembelajaran Project Based Learning (PBL) dapat meningkatkan kemampuan berpikir kreatif mahasiswa dalam mata kuliah seminar.

\section{DAFTAR PUSTAKA}

Anderson, L.W. \& Krathwol, D.R. (2001). A Taxonomy for Learning, Teaching and Assessing: A Revision of Bloom's Taxonomy of Educational Objectives. New York. Logman.

Antika, Rindi Novitri \& Nawawi, Sulton. (2017). Pengaruh Model Project Based Learning pada Mata Kuliah Seminar terhadap Keterampilan Berpikir Kreatif Mahasiswa. Jurnal Pendidikan Biologi Indonesia, 3 (1).

Baer, J. (1993). Creativity and Divergen Thinking: A Task Spescific Approach. Hillsdale, NJ: Lawrence Erlbarum Associates.

Bono, E. (2007). Revolusi Berpikir. Bandung: Kaifa.

Dharma, (2008). Kreativitas. Jakarta: Direktorat Tenaga Kependidikan, Direktorat Jenderal Peningkatan Mutu Pendidik dan tenaga Kependidikan Departemen Pendidikan Nasional.

Europan University Association. (2007). Creativity in Higher Education Report onthe EUA Creativity Project 2006-2007. Brussel Belgium: Europan University Association. 
Filasaime, Dennis, K. (2008). Menguak Rahasia Berpikir Kritis dan Kreatif. Jakarta: Prestasi Pustakaraya.

Hadzigeorgiou, Yannis. (2012). Thinking about Creativity in Science Education.Scientific Research: Creativity Education.

Munandar, Utami. (1999). Kreativtas dan Keterbakatan Strategi mewujudkanPotensi Kreatif dan Bakat. Jakarta: Gramedia Pustaka Utama.

Munandar, Utami. (2009). Pengembangan Kreativitas Anak Berbakat Jakarta:Rineka Cipta.

Nur, M. (2014). Berpikir Kreatif Surabaya: Penelitian Unggulan Perguruan Tinggi UNESA.

Riduwan. (2010). Skala Pengukuran Variabel-Variabel Penelitian cetakan ke VII. Bandung: Alfabeta.

Rule, Audrey C. (2012). Creativity and Thinking Skills Integrated into a Science Enrichment Unit on Flooding. Scientific Research: Creativity Education.

Starko, Alan, Jordan. (2010). Creativity in The Classroom.New Jersey: LEA Publishers.

Sugiyono, Sugiyono. Metode Penelitian Pendidikan:(Pendekatan Kuantitatif, Kualitatif Dan R \& D). Bandung: Alfabeta, 2008.

Torrence, E. Paul. (1965). Scientific Views of Creativity and Factors Affecting it's Growth. Daedalus, Vol. 94, No. 3, Creativity and Learning (Summer, 1965), pp. 663-681. American Academy of Arts \& Sciences: The MIT Press.

Thomas, J. W. \& Mergendoller, J.R. (2000). A Rreview of Reseacrch on Project Based Learning. California: The Aoutodesk Foundation 111 Mclnnis Parkway San Rafael. 
2021. BIO-CONS: Jurnal Biologi dan Konservasi. 3 (2):36- 